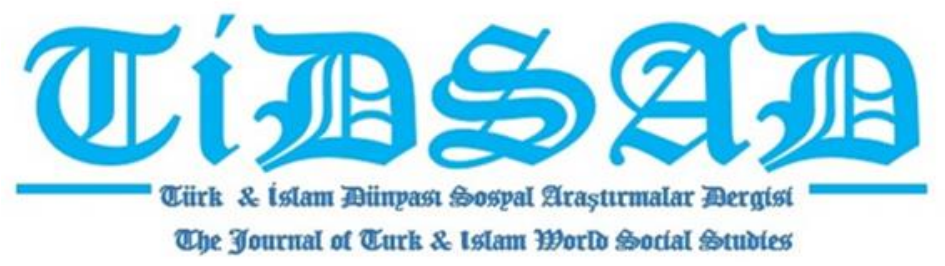

Yıl: 7, Sayı: 25, Haziran 2020, s. 90-97

Dr. Öğr. Üyesi Mustafa SOLMAZ

Van Yüzüncü Y11 Üniversitesi, Yabanc1 Diller Yüksekokulu, mustafasolmaz@yyu.edu.tr

\title{
TOPLUMLARDA KARTAL VE TUĞRUL KUŞU IMGELERI
}

\section{Özet}

Toplumların kendine özgü değerlerini yansıtan imgeler; inançtan mimariye sanattan düşünceye kadar yaşamın her alanında görülür. Tarih boyunca masallarda, destanlarda, mitlerde olduğu kadar yaşamın farklı alanlarında karşımıza çıkan imgelerden kuşlarla ilgili olanı hemen her toplumda vardır. Ancak, kültürlerin içerikleri ve sosyal değerlere bağlı olarak, her ne kadar aynı imgeye yüklenen anlam toplumlara göre değişse de, özellikle kartal ile tuğrul kuşu gibi bazı yırtıcı kuşlara yüklenen anlamlar benzerlik gösterir. Çalışmamızda; edebiyattan el sanatlarına, güzel sanatlardan bayraklara kadar insan yaşamının her alanında kendilerine yer bulan bütün kuşlara değinilmeyecek, hemen her kültürün vazgeçilmezlerinden olan kartal ve tuğrul kuşu imgelerinin bazı toplumlardaki yeri ile sınırlı olacaktır. Böylece, insanoğlunun ortaya çıkışından itibaren hem somut, hem de imgelerde soyut olarak, kuşlarla olan ilişkisi gösterilecek ve kültürler arasındaki etkileşim karşılaştırmalı olarak ortaya konacaktır. Araştırmamızın; karşılaştırmalı edebiyata destek veren diğer unsurlar gibi, karşılaştırmalı imge olarak alana katkı vereceği kanısındayız.

Anahtar Kelimeler: kartal, tuğrul kuşu, kültür, farkl1lık, benzerlik

\section{IMAGES OF EAGLE AND TUĞRUL BIRD IN SOCIETIES}

\begin{abstract}
Images reflecting the unique values of societies are seen in all areas of life, from belief to architecture to art and thought. Throughout history, among the images that we encounter in fairy tales, epics, myths, as well as in different areas of life, those relating birds exist in almost all societies. However, depending on the content of the cultures and social values, the meanings attributed to some predatory birds, such as the eagle and tuğrul bird, are similar, although the meaning attributed to the same image generally varies by society. In this study, all the birds that find
\end{abstract}


themselves in every area of human life, from literature to handicrafts, from fine arts to flags, will not be mentioned; it will be limited with the place of eagle and tuğrul bird images in some societies. Thus, the human beings' abstract and concrete relationship with birds from the beginning of the world will be shown, and the interaction between cultures will be presented comparatively. We believe that our research will contribute to the field of comparative image just like other elements that support comparative literature.

Keywords: eagle, tuğrul bird, culture, difference, similarity

\section{GíRiş}

İmgeler; içerdikleri anlam zenginliğinden dolayı, insanlık tarihinde, aktarılan unsurlar içerisinde sözcüklerden daha kalıcı ve etkileyici bir rol üstlenmişlerdir. Bunlardan en fazla öne çıkanlar; doğanın ayrılmaz bir parçası ve insan yaşamında önemli bir yere sahip olan hayvan imgeleridir. Sözlü ya da yazılı edebiyatta pek çok hayvan isminin geçmesi, onların rengini, şeklini ya da ses özelliklerini belirtmek için değil, teşbih yapmak, mecaz anlamında veya imge olarak kullanmak içindir. Hayvanların hem edebiyatta hem de sanat eserlerinde yer alması, insanoğlunun ona verdiği önemi ve ondan etkilendiğini gösterir. Toplumların sahip olduğu inanışlar, doğaya yönelik gözlemleri ve yaşam biçimleri hayvanlara farklı imgeler yüklemelerine neden olur. "Imgelerin de tarihi ve kültürel kökenleri vardır. (...) Imgeler tarihi kökenlere dayanmakla birlikte göreceli gerçekleri ifade ederler, kulaktan kulağa, nesilden nesile geçerler, toplumun dilinde yaşar, katmanlaşırlar. Bunları değiştirmek pek de kolay değildir" (Kefeli, 2000:29). Bazı hayvan imgeleri, genel olarak evrensel bir anlam taşıdığı için birçok toplumun kültürünün ayrılmaz bir parçası olmuş, kutsal bir imge haline dönüşmüştür.

Hayvanlar âleminin önemli üyelerinden olan kuşlardan bazıları her toplumda belirli imgelere karşılık gelirler. Gökyüzünde özgürce dolaşıp, aşılamaz gibi görünen dağları, denizleri kolayca aşan, erişilemez denilen mesafelere kolayca varabilen kuşlar, hemen her toplumun yaşamında, diğer hayvanlardan daha çok kendilerine yer bulmuşlardır. Kimi kuşun hile ile yavrusunu başkalarına büyüttürmesi, bülbülün yanık ötüşü, baykuşun viranelere tünemesi, bazılarının duruşundaki asaleti, bazılarının avına pençe atışı, bazılarının renk ve desen uyumu insanoğlunu etkilemiş, kültürünün ayrılmaz bir parçası halini almıştır. “... kuşlar çeşidine göre güzelliğin, iyiliğin, mutluluğun, şefkatin, sadakatin, dürüstlü̆̈̈ün, nezaketin, özgürlüğün, ön görülüğün, hürmet göstermenin, iyi bir aile bireyi olmanın, zorluklara karşı direnişin gibi birçok olumlu niteliğin yan sıra kibir, gurur, gösteriş, hile, aldatma, kötülük vb. kavramların sembolü olmuşlardır." (Buğrul, 2019:496) İnsanlar doğadan bugünkü kadar kopmadığ dönemlerde, iç içe yaşadığı varlıkların her halini gözlemlemiş, bulunduğu ortamı kolaylıkla terk edip uzak diyarlara istediği zaman uçarak gidebilen kuşlardan daha çok etkilenmiştir. Toplumlar, tarihin her döneminde kuşları sembol olarak kullanmış, sonraki dönemlerde yaşayan araştırmacılar da, bu imgelerden yola çıkarak halkların yaşadıkları doğal çevre ve mitolojileri ile ilgili bilgileri elde etmişlerdir.

\section{KUŞLAR}

Yaşamın hemen her alanında gördüğümüz kuşların masal, şiir, efsane, roman gibi edebiyat ürünlerine, anıt mezarlara, el sanatlarına, bayraklara ve birçok nesneye konu olması, insanlar ile kuşlar arasındaki ayrılmaz ilişkiyi gösterir. Farklı bilim dallarında, hem fiziksel 
varlıkları hem de çeşitli eğretilemeye araç oluşları yüzünden, kuşlarla ilgili motifler sıklıkla karşımıza çıkar. "Kuşlara ve kuşlar bağlamında farklı hayvanlara verilen olağanüstülükleri hemen her toplumun bulunduğu coğrafyanın ekolojik yapısina ve bunun sonucunda oluşan hayvan çeşitliliğine bă̆ll olarak oluşan değerler silsilesi içerisinde geliştirilen kültürel ürünlerde görmek mümkündür" (Öncül, 2009:176). Kuşlara verilen olağanüstü özellikler her toplumun yapısı ve bulunduğu coğrafyanın yapısına göre çeşitlilik gösterir. Her ne kadar farklı kültürdeki kuş imgeleri değişiklik gösterebilse de kartal ve tuğrul kuşu gibi bazı yırtıcı kuşlar, hemen her kültürde görülür.

Kuş motiflerine yüklenen anlam, toplumlara göre farklılık gösterebilir. Kültürlerde, kuşların her birinin özelliğine göre bir anlamsal değer biçilmiş, o toplum, kendi kültür ve sanat değerlerinde ona, bu anlama uygun biçimde yer vererek nesilden nesile aktarmıştır. "Kuşlar genel olarak, göklerin, ruhsal yükselmenin, yüksek şuur hallerine geçişi, ortamdaki yükselişi, dünyasallıktan uzaklaşmanın, hafifliğin, semaviliğin, ruhların, ruhsal unsurların, ruhsal tesirlerin, sezgi ve ilhamın, reenkarnasyonun, ruhun ebediliğinin, Gök ile Yer arasindaki irtibat ve aracıllğın sembolleri olarak da kullanılmıştır." (Salt, 2006:228) Kimi kültürlerde uğur olarak görülen bir kuş, bir başka kültürde kötülüğün kaynağı olarak görülebilir. Ancak kartal ve tuğrul kuşu gibi efsanevi kuşların, farklı uygarlıklarda değişik adlarla anılsalar da, birçok özelliklerinin bu kültürlerde ortak olduğu görülür.

Türklerde, kuşlara verilen özellik neredeyse, günlük yaşamın her alanında karşımıza çıkar. Bazen gelecekten müjdeler getiren "Bir Han'ın erkek çocuğu olmuyor. Kayın ăgacına konmuş bir kuş Han'a, senin bir oğlun olacak, ..." (Ögel, 1995:548) diye haber veren bir haberci olarak karşımıza çıkar. Bazen de “... iyilik getiren uğurlu bir hayvandır. (...) ölen insanın bedeninden ayrılan bir ruh olarak ..." (Sever, 1999:86) görülür. Türklerin yırtıcı kuşları sembol olarak seçmeleri, güçlü Gök Tanrı inançları ile ilişkilidir. Tanrının gökte olduğunu düşünmeleri ile güçlü kuşların gökyüzü hâkimiyetleri arasında ilişki kurarak, inançlarına ve mitolojik değerlerine verdikleri önemden dolayı onlara bayraklarında, güzel sanat eserlerinde, türkülerinde yer vermişlerdir. Kuşların göklerde uçmalarından dolayı, onları gök tanrının temsilcisi olarak görmüşler ve koruyucu ruh olarak kabul etmişlerdir. Bu yüzden kuşlar; Göktürk, Uygur, Avrupa Hun Devleti, Saha Türkleri ile Altaylardaki diğer topluluklar başta olmak üzere birçok Türk hükümdar ya da beyinin sembolü olmuştur. Batı uygarlığında ise, yeniden doğuş, gurur, güç, gösteriş gibi nedenlerden dolayı imge olarak kullanılmışlardır.

\section{KARTAL}

Bireylerin oluşturduğu halk kitlelerinin, binlerce yıl koruyup sakladığı alışkanlıklarını inanç, gelenek, mimari, el sanatları gibi maddi ve manevi unsurlarla geleceğe aktarmasıyla ortaya çıkan kültür, toplumların kimliğini oluşturur. Geçmişten günümüze kadar Türk kültüründe; ruhu, ölümsüzlüğü, sevinci ve mutluluğu temsil eden kuş motiflerinin önemli bir yeri vardır. Bu imge; özellikle mezar taşlarından minyatür sanatına, kabartmalardan süslemelere kadar yaşamın birçok alanında kullanılmıştır. Türk kültüründe kartal ve çift başlı kartalın ayrı bir yeri olduğu; İskitler, Hunlar, Göktürkler, Uygurlar, Saha Türkleri, Selçuklular gibi hemen her Türk boyunda arma, bayrak ya da el sanatlarında kullanılmasından kolayca anlaşılabilir.

Binlerce yıldır insanoğlunun yaşamında yer alan, genellikle özgürlük, güç ve kudreti temsil eden kartallar şiirlere, romanlara, efsanelere konu olmuştur. Bu nedenle de tarih boyunca 
birçok uygarlığın kültür ve sanat unsurlarında kullanılmıştır. Özellikle Orta Asya da önemli bir yere sahip olan, Kırgızların Er Töştük destanında Karakuş olarak geçen, Altay mitolojisinde Tanrı Ülgen'in oğlu olarak görülen (Çoruhlu, 2000:132) kartal, Şamanların ayinlerinde kullandıkları davullar üzerinde de kendisine yer bulur. Kartalın kutsallığından ve gücünden yaralanmak isteyen "Şamanlar kartal kimliğine bürünmek suretiyle kötü ruhlarla daha iyi mücadele edecek ve amacına daha rahat ulaşabilecektir." (Hoppal, 2012:261) Böylece, onun uçma yetisi sayesinde, gök tanrıyla kolayca iletişim kurabilecektir. İnançla bağdaştırılan kuşların uçma özelliği bu dünyanın sınırlarını aşan ruhları simgelemektedir.

Rus etnograf Lev Yakovlevich Sternberg, Sibirya'da bulunan halkların kartalın, pençeleriyle iri bir hayvanı göklere çıkaran gücünden dolayı, diğer yırtıcılardan farklı bir yere koyduğunu ve büyük sayg1 gösterdiğini (Sternberg, 1925:718) belirtmektedir. Yakut Türklerinde Şamanlar; kendi ruhları olgunlaşıncaya kadar ruhlarını farklı türde birer hayvanla temsil ederler. Kartal en yüksek ruhu taşıyan hayvan olduğu için de "Türk topluluğunu yansıtan kuş sembolü Altay ve Yakut kabileleri ile Oğuz boylarında yaygın olarak kullanılmıştır" (Ögel, 1993: 47). Ayrıca, “Avrupa Hun Devletinde kartal gök tanrı olarak görülmektedir" (Öney, 1971:158) Saha Türkleri ise, duydukları saygıdan dolayı, kartal gördüklerinde kurban keserek etin bir kısmını ona sunmaktadırlar. Farklı coğrafya ve kültürlerde kartal kadar saygı gören bir başka kuş yok denebilir. Günümüzde bile, Kazakistan ve Moğolistan'ın batısında kartal beslemek ve onunla avlanmak önemli uğraşlardan birisidir.

Diğer yırtıc1 kuşlar gibi Türk kültüründe önemli bir yere sahip olan kartalın, “Orta Asya Türk inanışlarında (...) tanrı sembolü olduğu, Türk boylarının kendilerine birer yırtıcı kuşu ongun olarak seçtikleri bilinmektedir." (Çal, 2011:236) İslamiyet'ten önce olduğu gibi sonrasında da hükümdarlık imgesi olarak güç ve kuvveti temsil etmiş, bazen de arma olarak kullanılmıştır. (Seyfeli, 2003:48) Çift başlı kartal Türklerde; Selçuklularda olduğu gibi, güç birliğini, her yöne hakim olma durumunu temsil etmiştir.

Batı uygarlı̆̆ında da görülen kartal Roma'dan günümüze kadar birçok milletin bayrağında ya da armalarında görülür. Çünkü "Hıristiyan sembolizminde kartal, yeniden doğuşu, cömertliği, gücü ve gururu simgeler." (Çoruhlu, 2014:63) Bu yüzden; Prusya, Polonya, Rusya, Fransa gibi ülkelerin armalarında da kartal vardı. Günümüzde dahi bu imge kullanılmaya devam etmekte, hatta Arnavutluk, Kazakistan, Misır, Moldova, Zambiya gibi bazı ülkelerin bayraklarında yerini almaktadır.

Kartallar, masallarda bazen iyi bazen de kötü olarak karşımıza çıkar. Bostancı Dede masalında şehzadeyi sırtında taşıyan kartal, Çuvaş masallarında kahramanı öbür dünyadan kurtarmak için sırtına alır (Salmin, 1994:281). Eskimo masalında, ölen kartal bir adaya dönüşürken (Sangi, 1985:378-383), Nijer masalında ateş saçan gözleri, keskin pençeleri ve ekin yığınlarını bir lokmada yutan (Hama, 1985:121-126) yırtıcı acımasız bir kuşa dönüşür.

\section{TUĞRUL KUŞU}

Destan, efsane ve masallarda; kartal gibi güçlü yırtıcı kuşlardan başka, geçmişten günümüze hiç var olmamış canlılardan da söz edilmiştir. Havada, karada ya da suda olduğu söylenen bu yaratıklardan en fazla öne çıkanlar, insanoğlunun yapamadığ 1 uçma işini gerçekleştiren kuşlardır. Değişik kültürlerde, bu mitolojik kuşların adları farklı da olsa, 
özellikleri ve yaptıkları işler birbirine benzemektedir. Mısır ve Batı mitolojilerinde pheniks, İran mitolojisinde Simurg, İslam öncesi Arap mitolojisinde Anka ve Türk mitolojisinde dönemlere göre farklı adlar alan Tuğrul kuşu kültürlerin ortak imgesidir.

Gerçekte olmayan; ancak Anka, Zümrüdüanka, Devlet kuşu, Simurg, Sirenk, Hüma, Phenix, diye de anılan, değişik kültür ve dillerde düşsel bir varlık olarak yaşayan Tuğrul kuşu, insanların kafasında büyük anlamlar ifade eden bir varlıktır. Çoğu doğu kültüründe Kaf dağının tepesinde ya da ardında yaşadığına inanılan kuşun yaradılışı ve fiziksel yapısı ile ilgili farklı anlatımlar vardır. "Kendini küllerinden var eden Anka kuşunun dünyada sadece bir tane olduğuna inanılır" (Gezgin, 2007:20) Saltuk-name'de anlatılanlara göre Sar1 Saltuk; Kafdağı'nda bulunan ve İslamiyet öncesi kutsal sayılan kayın ağacının yanına gelir. Ağacın üzerinde bulunan Simurg (Tuğrul) kuşunun yavrularını yemek isteyen ejderhayı öldürür. Biraz sonra gagasında iki fil taşıyarak gelen anne kuş Sarı Saltuk'u öldürmek isterken yavruları buna engel olur. (Alsan, 2005:93) Kırgızların Er Töştük destanına göre; Er Töştük sefer dönüşü yurduna geri dönerken Kafdağı'na gelir. Burada gökyüzüne kadar uzanan ulu çınar ağacındaki Karakuş yuvasını görür. Yuvalarına kendilerini yemek için gelen ejderi gören iki yavru kuş ağlamaya başlar. Bunu gören Er Töştük, Karakuş’un yavrularını her sene yiyen ejderi parçalayıp yavrulara yedirir. Bunun karşılığında anne kuş ona yardım eder (İnan, 1987:350). Destandan da anlaşılacağı üzere, çok eski dönemlerden beri Türklerde Karakuş (Tuğrul kuşu) imgesi vardır. Türk mitolojisinde doğaüstü özellikleri olan kızıl renkli devasa bir kuştur ve tüyleri sihirlidir. Fars mitolojisinde Simurg olarak geçen bu kuş, Alburz dağında yaşamaktadır, ailesi tarafından terk edilen tanrı Zal'ı kurtararak onu büyütmüştür.

Antik Misır ve yunan mitolojilerinde Phenix olarak geçen Tuğrul kuşu devasa boyutlardadır. “... Arabistan'da doğmuş olmasına rağmen ailesini unutmak için Yunanistan'a uçtuğunu söylemektedir. Sadece nemden beslenen bu kuş, mor bir bedene, altın boyuna ve mavi kuyruğa sahipmiş. Onun altın tüylerini bulan kimsenin güzel bir talihe sahip olacağına inanılmaktaymış" (Coleman, 2007:827). Coleman'dan farklı olarak bu kuşun, “... Antik Yunan'da Güneş Tanrlsı'nın tezahürü olduğunu” (Biedermann 1989:261), “eski Mısır'da ise güneş döngüsünün bir sembolü olduğunu" (Chevalier-Gheerbrant, 1996:752) söyleyen araştırmacılar da vardır.

Bazı araştırmacılar, Türk topluluklarının masal ve destanlarında uzun bölümler halinde yer alan Anka kuşunun, Arapça 'Anka', Farsça 'Simurg' olan adının Türkçeye Zümrüdüanka şeklinde geçmesinden dolayı Arap ya da İran edebiyatlarından geçmiş olabileceğini söylerler. "İslam-İran edebiyatı Tuğrul, Alp Karakuş veya Songur adll, eski Türk masal ve efsanesindeki, Türklerin kendilerine mahsus büyük kuşunun yerine Simurg'u sokmuş olsa gerektir" (İnan, 1987:350). Çünkü bu efsane Türk kavimleri arasında İslam öncesinde yaygın olarak bulunmaktadır.

Bazı oğuz boylarının bayraklarında Tuğrul kuşu yer almışırı (Kurtoğlu, 1987). Avrupa Hun imparatorluğu soyundan olan "Macar geleneğinde bu kuşun başıına bir de taç koyulmuştur. Kral Geza zamanındaki Macarlar bu armayı tüm her yerde kullanmışlardır" (Ögel, 1993:592) Her ne kadar yeniden doğma süreleri farklı olsa da, bütün mitolojilerde ortak olan, bu kuşun kendisini yakarak küllerinden yeniden doğmasıdır. Farklı adlarla anılan bu kuşa tarihi boyutuyla bakıldığında, mitolojik olarak öncelikle, Hint, İran ve Türk masallarında karşılıklı etkileşim 
sonucu ortaya çıktığı, daha sonra Arap kaynaklarının etkisinde kaldığı (Duymaz, 1998) söylenebilir. "Türk mitolojisinde hem alıc hem de kut özellikleri olan "karakuş" ile ilgisi olabileceği söylenmektedir. Ayrıca devlet ve saadet kuşu olan "Hümâ" eski Türk inanışlarındaki dişi ilâhe "Umay" ile benzerlik taşımaktadır" (Ceylan, 2015:6) "Göktürklerde anka, mezarlara işlenen önemli bir figürdür" (Çal, 2005:535) Türklerde, dönemlere göre adı farklılık gösterse de, Tuğrul kuşunun özellikleri hep aynıdır.

Tuğrul kuşu, fiziksel yapısından dolayı çok yüksekten uçması, elde edilemeyişi, tuzağa düşmemesi, kemikle beslenmesi (Batislam, 2002:185-208) gibi nedenlerden dolay1, divan şiirinde diğer kuşlardan üstün görülür. Çeşitli dinsel ve büyüsel etkileri bulunduğuna inanılan bu mitolojik kuş, kaynağı eski Mısır inançlarında bulunmakla beraber Çin'den İran mitolojisine ve Müslümanlıktan Hıristiyanlığa kadar geniş bir inanç alanında yer almaktadır (Hançerlioğlu, 1984:758) Erken Hıristiyanlık literatürüne göre bu kuş “... ölüme yaklaştığını hissettiği zaman (...) aromatik bitkileri toplamakta ve bu aromatik bitkiler içinde güneşin tutuşturduğu bir ateş tarafindan yanmaktadır. Kalan aromatik küllerin içinden phoenix kuşu yeniden doğmaktadır" (Van Den Broek, 1971:146)

Ortak özelliklerine bakıldığında; Batı, Mısır ve İslam öncesi Arap mitolojilerinde kendini yakıp küllerinden doğarken, Türk mitolojisinde bazen ölümlü bazen ölümsüz olduğu görülür. Renkleri; Batı ve Mısır mitolojisinde boğazından başlayarak ayak bileklerine kadar olan kısım safran, kuyruğu mavi, kanatları ve kalan kısmı mor ve pembe tüylerden oluşmakta iken, Türk mitolojisinde altın kanatlı, mavi renkli, üzerinde benekler olduğu şeklindedir (Roux, 2012:144). İslam öncesi Arap mitolojisinde ise tüyleri farklı renklerde ve parlaktır. Büyüklügü; Batı ve Mısır mitolojisine göre kanatlarını açtı̆̆ında gökyüzünü karartacak kadar büyük iken, İslam öncesi Arap ve Fars mitolojisinde otuz kuş büyüklüğündedir. Türk mitolojisinde ise, uçtuğunda şiddetli yağmurlar, fırtınalar, şimşekler çıkarmaktadır. Yuvası; batı ve Mısır mitolojisine göre Heliopolis kentinde, Fars mitolojisine göre Elburz dağında, Türk mitolojisine göre Kafdağı'nda ya da yazın Yeşil Kaya, kışın Kızıl Kaya'dadır. İslam öncesi Arap mitolojisinde ise Feth Dağı'ndadır.

\section{SONUÇ}

Sözlü ve yazılı edebiyat unsuru olmasının yanında yaşamın her alanında karşımıza çıkan imgeler, anlatılarını ya da beğenilerini sanatsal bir şekilde veya olağanüstüleştirerek ortaya koymada insanoğluna birer yardımcı gibidirler. Edebiyat ve sanatta hayal etmenin sınırı olmadığından, bu eserlerde yer verilen, gerçek ya da hayali, canl1-cansız her tür varlığın sembolik bir önemi vardır. Binlerce yıldır kuşaktan kuşağa aktarılan efsaneler, mitler, sanat eserleri geçmiş dönemlerde kalmış olsalar bile, içlerinde taşıdıkları imge ya da semboller her toplumun gelecekteki yaşantısına etki ederler.

Tarih boyunca insanların hayvanlar âlemiyle ilişkisi, hemen her kültürde, onları sadece besin kaynağı olarak görmeleriyle ilgili olarak değil, aynı zamanda, mitolojik figür, sanat eserlerinde esin kaynağı, güç ve bilgelik sembolü olarak görmeleriyle ilgilidir. Bunlar içerisinde kuşların, belki de insanoğlu uçamadığı için, yaşamlarında ayrı bir önemi vardır. Gücü ve hâkimiyeti gösteren kartalın somut olmasının yanında, soyut bir kavram olarak tuğrul kuşunun da hemen her toplumun mitlerinde bulunmasının, aslında kültürlerin kökeninin aynı kaynaktan 
beslendiğini, ancak zamanla çevrenin ve dış etkenlerin değişmesiyle bazı farklılıklar oluştuğunu göstermektedir demek mümkündür.

Farklı kültürlere sahip olmalarına, değişik coğrafyalarda bulunmalarına rağmen, kartalın bazı toplumlarda özgürlügün sembolü olan bayraklarda kullanılması bunu destekler. Kartal ve Tuğrul kuşunun her toplumda benzer anlamlarda imge olarak görülmesi, toplumların inanç sistemlerine dahi nüfuz etmesi ise, insanlığın kuşlar âlemiyle ilişkisinin, besin kaynağ1 olmasının dışında, takip edemediğimiz tarihin karanlık dönemlerine kadar gittiğini, doğanın insanlar üzerindeki etkisini gösterir. Bu etki, kartal ve tuğrul kuşu ile zirveye ulaşır.

\section{KAYNAKLAR}

Alsan, Şenay (2005). Türk mimari süsleme sanatlarında mitolojik kaynaklı hayvan figürleri. Doktora Tezi, Marmara Üniversitesi, Türkiyat Araştırmaları Enstitüsü, İstanbul.

Batislam H. Dilek (2002). Divan Şiirinin Mitolojik Kuşları: Hüma, Anka, Simurg. Türk Kültürü İncelemeleri Dergisi 1, İstanbul.

Biedermann, Hans (1989). Dictionary of Symbolism: Cultural Icons and the Meanings Behind Them. USA: Plume

Buğrul, Hasan (2019.) Van-Hakkâri İlleri Kültür ve Sanatında Kuşlar. Uludağ Üniversitesi FenEdebiyat Fakültesi Sosyal Bilimler Dergisi, C. 20, S. 36, s. 477-512.

Ceylan, Ömür (2015). Kuşlar Divanı-Osmanlı Şiir Kuşları. İstanbul: Kapı Yayınları.

Chevalier, Jean; Gheerbrant, Alain (1996). The Penguin Dictionary of Symbols. London: Penguin Books.

Coleman, J.A. (2007). The Dictionary of Mythology An A-Z of Themes, Legends and Heros. London: Arcturus Publishing Limited.

Çal, Halit (2005). Orhun Anıtları 2000 Yı1ı Kazısı: Karakuş Tasvirli Sembolik Lahit. XIV. Türk Tarih Kongresi 9-13 Eylül 2002 Kongreye Sunulan Bildiriler, 3.cilt, 2005:525-550.

Çal, Halit (2011). Erzincan Çayırlı İlçesi Mezarlarında Kuş Motifi. Millî Folklor, Sayı 89.

Çoruhlu, Yaşar (2000). Türk Mitolojisinin Ana Hatları. İstanbul: Kabalc1

Çoruhlu, Yaşar (2014). Türk Sanatında Hayvan Sembolizmi. Konya: Kömen Yayınları

Duymaz, Ali (1998). Mitolojik Bir Kuş: Zümrüdü Anka. Balıkesir Üniversitesi Sosyal Bilimler Enstitüsü Dergisi C. 1 S. 1, s. 91-97

Gezgin, Deniz (2007). Hayvan Mitoslar1. İstanbul: Sel

Hama Boubou, (1985). İzé-Gani. Edition Présence Africaine.

Hançerlioğlu, Orhan (1984). İslam İnançları Sözlügü. İstanbul: Remzi Kitabevi

Hoppal, Mihaly (2012). Avrasya'da Şamanlar. Çev. Bülent Bayram, H. Şefket Çağatay. İstanbul: Yap1 Kredi

İnan, Abdulkadir (1987). Türk Folklorunda Simurg ve Garuda. Makaleler ve İncelemeler, Ankara: TTK Basımevi 
Kefeli, Emel (2000). Karşılaştırmalı Edebiyat İncelemeleri. İstanbul: Kitabevi

Kurtoğlu, Fevzi (1987). Türk Bayrağı ve Ay yıldız. Ankara: Türk Tarih Kurumu Yayınları

Ögel, Bahaeddin. (1993) Türk Mitolojisi I. Cilt. Ankara: Türk Tarih Kurumu Basımevi

Ögel, Bahaeddin. (1995) Türk Mitolojisi II. Cilt. Ankara: Türk Tarih Kurumu Basımevi

Öncül, Kürşat (2009). Masallardaki Devlet Kuşu Motifi. Milli Folklor Dergisi, Say1 84.

Öney, Gönül. (1971). Anadolu Selçuk Mimarisinde Avcı Kuşlar Tek Ve Çift Başlı Kartal, Malazgirt Armağanı. Ankara.

Roux, Jean-Paul (2012). Eski Türk Mitolojisi. Çev. Musa Yaşar Sağlam. Ankara: Bilgesu Yayıncilik.

Salmin, A. K. (1994). Narodnaya Obryadnost Çuvaşey. Çeboksarı.

Salt, Alparslan (2006). Neo-spiritüalist Yaklaşımlarla Ezoterik Bilgilerin Işı̆̆ında Semboller. İstanbul: Ruh ve Madde Yayıncılık ve Sağlik Hizmetleri A. Ş.

Sangi, V. M. (1985). Legendi i Mifi Severa. Moskova

Sever, Mustafa, (1999). Türk Mitolojisinde Kuşlar. Millî Folklor, S. 42, Yaz.

Seyfeli, Canan (2003). Türk Mitolojisinde Hayvan Motifleri. Yol Bilim Kültür Araştırma, Sayı 23, Mayıs-Haziran.

Sternberg, Lev Yakovlevich (1925). Kult Orla U Sibirskih Narodov (Sibirya halklarında kartal kültü) Etyud Po Sravnitelnomu (karşılaştırmalı çalışma). Sbornik Muzeya Antropologii i Etnografi. Leningrad. Cilt. V, Sayı. 2.

Van Den Broek, Roelof (1971). The Myth of The Phoenix. Leiden:E. J. Brill. 